\title{
Beta cell-specific $Z$ Znt8 deletion in mice causes marked defects in insulin processing, crystallisation and secretion
}

\author{
N. Wijesekara • F. F. Dai • A. B. Hardy • P. R. Giglou • \\ A. Bhattacharjee $\cdot$ V. Koshkin $\cdot$ F. Chimienti $\cdot$ \\ H. Y. Gaisano • G. A. Rutter • M. B. Wheeler
}

Received: 18 November 2009 / Accepted: 5 February 2010/Published online: 28 April 2010

(C) Springer-Verlag 2010

\begin{abstract}
Aims/hypothesis Zinc is highly concentrated in pancreatic beta cells, is critical for normal insulin storage and may regulate glucagon secretion from alpha cells. Zinc transport family member 8 (ZnT8) is a zinc efflux transporter that is highly abundant in beta cells. Polymorphisms of ZnT8 (also known as SLC30A8) gene in man are associated with increased risk of type 2 diabetes. While global Znt8 knockout (Znt8KO) mice have been characterised, ZnT8 is also present in other islet cell types and extra-pancreatic tissues. Therefore, it is important to find ways of understanding the role of ZnT8 in beta and alpha cells without
\end{abstract}

N. Wijesekara, F. F. Dai and A. B. Hardy contributed equally to this study.

Electronic supplementary material The online version of this article (doi:10.1007/s00125-010-1733-9) contains supplementary material, which is available to authorised users.

N. Wijesekara • F. F. Dai • A. B. Hardy • P. R. Giglou •

A. Bhattacharjee $\cdot$ V. Koshkin $\cdot$ M. B. Wheeler $(\bowtie)$

Department of Physiology, University of Toronto,

1 King's College Circle Room 3352,

Toronto, ON, Canada M5S 1A8

e-mail: michael.wheeler@utoronto.ca

H. Y. Gaisano

Department of Medicine, University of Toronto,

Toronto, ON, Canada

F. Chimienti

Mellitech,

Grenoble, France

G. A. Rutter

Section of Cell Biology, Division of Medicine,

Imperial College London,

London, UK the difficulties caused by the confounding effects of ZnT8 in these other tissues.

Methods We generated mice with beta cell-specific (Znt8BKO) and alpha cell-specific (Znt8AKO) knockout of $Z n t 8$, and performed in vivo and in vitro characterisation of the phenotypes to determine the functional and anatomical impact of ZnT8 in these cells. Thus we assessed zinc accumulation, insulin granule morphology, insulin biosynthesis and secretion, and glucose homeostasis.

Results Znt8BKO mice are glucose-intolerant, have reduced beta cell zinc accumulation and atypical insulin granules. They also display reduced first-phase glucose-stimulated insulin secretion, reduced insulin processing enzyme transcripts and increased proinsulin levels. In contrast, Znt8AKO mice show no evident abnormalities in plasma glucagon and glucose homeostasis.

Conclusions/interpretation This is the first report of specific beta and alpha cell deletion of Znt8. Our data indicate that while, under the conditions studied, ZnT8 is absolutely essential for proper beta cell function, it is largely dispensable for alpha cell function.

Keywords Alpha cell - Beta cell · Glucagon - Insulin ·

Pancreatic islets $\cdot \mathrm{SLC} 30 \mathrm{~A} 8 \cdot \mathrm{Zinc} \cdot \mathrm{ZnT}$ 8

\begin{tabular}{ll}
\multicolumn{2}{l}{ Abbreviations } \\
Gcg & Glucagon \\
Gcg-Cre- & Glucagon promoter-Cre- \\
YFP & ROSA26EYFP \\
HOMA-IR & HOMA for insulin resistance \\
qPCR & Quantitative real-time PCR \\
RIP & Rat insulin promoter \\
YFP & Yellow fluorescent protein \\
ZnT8 & Zinc transport family member 8 \\
Znt8AKO & Alpha cell-specific Znt8 knockout
\end{tabular}


Znt8BKO Beta cell-specific Znt8 knockout

Znt8KO Global Znt8 knockout

Znt8loxP Conditional Znt8 mice

\section{Introduction}

Zinc transport family member 8 (ZnT8) is a member of the cation diffusion facilitator family and a zinc efflux transporter recently linked to type 2 diabetes [1-5]. Since then, ZnT8 has also been found to be targeted by autoantibodies in type 1 diabetic patients [6]. Interestingly, studies suggest that the risk allele of ZnT8 (also known as $S L C 30 A 8)$ is associated with reduced insulin secretion in type 2 diabetic patients [7, 8]. The important role of zinc in modulating insulin biosynthesis and secretion [9], and the unique localisation of ZnT8 with insulin [10, 11] have focused much interest on determining the function of $\mathrm{ZnT} 8$ in controlling glucose homeostasis.

The generation of global Znt8 knockout (Znt8KO) mice has provided an excellent tool to better study the link between diabetes and ZnT8. These mice are glucoseintolerant with abnormalities in zinc accumulation, insulin granule morphology and insulin secretion from beta cells [12-14], although some differences in phenotypes exist between groups. Interestingly, on a high-fat diet, Znt8KO mice were severely insulin-resistant and more obese than controls, suggesting that ZnT8 may play a role in peripheral tissues. Thus, glucose intolerance may not necessarily result from the absence of ZnT8 in beta cells alone. Although ZnT8 was originally thought to be pancreas-specific $[11,15]$, studies now suggest it is also present in human adipose tissue [16], blood lymphocytes [17] and the cubical epithelium that lines thyroid follicles and adrenal cortex [18]. We have also shown that ZnT8 is present in alpha cells $[13,19]$. However, its function there remains unknown as although zinc is localised to alpha cell granules [20], zinc is not thought to be required for glucagon processing and packaging. Interestingly, a recent study showed that overexpression of Znt8 inhibits, while knockdown stimulates, glucagon secretion in cultured mouse alpha cells [21], suggesting that glucagon secretion may be regulated directly by $\mathrm{ZnT}$, thus indirectly affecting insulin secretion. It is therefore important to devise ways to understand the role of ZnT8 in beta cells without the problem of confounding effects from other tissues including alpha cells. The insights gained from such studies might also begin to explain the marked phenotypic differences between different colonies of Znt8KO mice [12-14]. Finally, as some [19, 22-24], though not all $[13,25]$ previous studies suggest that glucagon secretion might be regulated by zinc released from beta cells, it is also important to study the impact of $\mathrm{ZnT} 8$ on alpha cell function.
In this study, we generated mice with beta cell-specific (Znt8BKO) and alpha cell-specific (Znt8AKO) knockout of $Z n t 8$. We show that Znt8BKO mice are glucose-intolerant with reduced beta cell zinc accumulation, abnormal beta cell granule morphology and impaired insulin processing. Reduced first-phase insulin response to glucose was also evident compared with controls, suggesting impaired insulin secretion. In contrast, Znt8AKO mice showed no detectable phenotypic differences compared with control mice.

\section{Methods}

Generation of cell-specific Znt8 knockout mice Chimeric males were bred with $\mathrm{C} 57 \mathrm{Bl} / 6 \mathrm{~J}$ wild-type mice to generate heterozygous mice carrying the floxed allele. These animals were then mated with pCAG-Flp-expressing C57Bl/6J mice to excise the FRT flanked neomycin cassette and generate neomycin-excised conditional ZnT8 mice (Znt8loxP). The loxP sites flank exon 1, which contains the start codon for Znt8. Homozygous mice crossed to cell-specific Cre mice therefore lack Znt8 in that cell type. Znt8loxP mice were obtained from Genoway, Lyon, France. To generate Znt8BKO mice, Znt8loxP mice were crossed to rat insulin promoter (RIP)-Cre mice. Since RIP promoter can also drive deletion in the hypothalamus [26], Znt8 expression was determined in this tissue and found to be low, but detectable in quantitative real-time PCR (qPCR) analysis (Fig. 2c). To generate Znt8AKO mice, Znt8loxP mice were crossed to glucagon promoter (Gcg)-Cre-ROSA26EYFP (Gcg-Cre-YFP) mice [27]. This cross allows labelling of alpha cells with YFP where $\mathrm{Cre}$ is expressed. Mice were genotyped using tail DNA and standard multiplex PCR using flox and Cre primers (Electronic supplementary material [ESM] Table 1). Mice expressing Cre transgene alone were used as controls (RIP-Cre mice were controls for Znt8BKO mice and Gcg-Cre-YFP mice were controls for Znt8AKO mice) and 6- to 8-week-old male mice were used for all experiments, unless otherwise mentioned. All experiments were approved by the Animal Care Committee at the University of Toronto and animals were handled according to the guidelines of the Canadian Council of Animal Care.

Islet isolation and dispersion Mouse islets were isolated by collagenase digestion of the mouse pancreas and dispersed as described [28]. Human islets isolated following the Edmonton Protocol [29] from healthy donors were provided by J. Shapiro and the ABCC Human Islet Distribution Program (Clinical Islet Laboratory, University of Alberta, Edmonton, AB, Canada). Human islets were dispersed as described [30]. 
Transmission electron microscopy Islets were prepared and images were acquired as described [13]. Dense core, empty, light core (grey) and atypical (rod-shaped) granules were manually counted and quantified.

Immunogold-cryo electron microscopy Cryo-electron microscopy and immunogold labelling of ZnT8 was performed as described [31]. Based on insulin and glucagon immunogold labelling and literature on granule characterisation [32], cells within the centre of the mouse islet with granules containing a dense core and a large translucid halo were identified as beta cells, while peripheral cells of the mouse islet with granules containing a dense core and a thin rim halo were identified as alpha cells. Human beta cells were identified strictly by the large translucid halo.

Western immuno-blot analysis Western blot analysis was performed as described [13]. Lysates were resolved by $10 \%$ (wt/vol.) SDS-PAGE and immunoblotted with polyclonal anti-ZnT8 (1:500; Mellitech, Grenoble, France) or anti-beta actin $(1: 2,000)$ antibodies followed by anti-rabbit secondary antibody (both from Sigma, St Louis, MO, USA). Immunoblots were scanned on a Kodak imager (Molecular Imaging Systetms, Carestream Health Inc., Rochester, NY, USA) within the linear range of intensity.

Quantitative real-time PCR This was performed as described $[19,30]$. Primers are listed in ESM Table 1. Data were normalised to mouse beta actin mRNA.

Immunostaining and confocal microscopy Dispersed islet cells were fixed in 4\% (vol./vol.) paraformaldehyde for 15 min, permeabilised with $2 \%$ (vol./vol.) Triton-X-100 for $10 \mathrm{~min}$ and blocked overnight in $5 \%$ (wt $/ \mathrm{vol}$.) BSA at $4{ }^{\circ} \mathrm{C}$. Cells were then labelled overnight at $4^{\circ} \mathrm{C}$ with polyclonal anti-ZnT8 (1:300) and anti-insulin (0.05 mol/l; DAKO, Glostrup, Denmark), and monoclonal anti-glucagon (1:300; Sigma) and anti-green fluorescent protein (GFP; 1:300, Santa Cruz Biotechnology, Santa Cruz, CA, USA) antibodies. Cells were then stained at room temperature for 30 min with Cy5-conjugated anti-rabbit, FITC-conjugated anti-guinea pig or FITC-conjugated anti-mouse secondary antibodies (Jackson ImmunoResearch Laboratories, West Grove, PA, USA) respectively [13, 19]. Finally, cells were washed and mounted on glass slides, and images acquired using a software package (LSM510; Zeiss, Thornwood, NY, USA) on a confocal microscope with $488 / 633 \mathrm{~nm}$ excitation laser line and $545 \mathrm{~nm}$ beam-splitter.

Oral glucose tolerance test Following a $6 \mathrm{~h}$ fast, glucose $(1.5 \mathrm{~g} / \mathrm{kg}$ body weight) was given by oral gavage and blood glucose measured from tail vein blood at $0,10,20,30,60$, 120 min using a glucometer. For insulin and proinsulin quantification, blood from the tail vein was collected in EDTA-coated microvettes (Sarstedt, Nümbrecht, Germany) at $0,10,30,60$ and $120 \mathrm{~min}$. Area under the curve was calculated using a software package (Graph Pad Prism, La Jolla, CA, USA). HOMA for insulin resistance (HOMA-IR) index was calculated in the fasting state [13].

Glucagon, insulin and proinsulin measurements Blood was collected from a tail vein of $16 \mathrm{~h}$ fasted mice for glucagon measurements. Plasma was separated from whole blood by centrifugation for $10 \mathrm{~min}$ at $5,900 \times \mathrm{g}$. Plasma insulin, and islet and plasma proinsulin were measured using ELISA kits (ALPCO Diagnostics, Salem, NH, USA; Mercodia, Uppsala, Sweden respectively). Proinsulin detection was performed according to manufacturer's instructions: Proinsulin in the sample reacts with anti-proinsulin antibodies bound to microtitration wells and to peroxidase-conjugated antibodies in the solution. The bound conjugate is detected by reaction with $3,3^{\prime}, 5,5^{\prime}$ tetramethylbenzidine. The kit detects proinsulin I and II. Islet insulin content and plasma glucagon were measured by radioimmunoassay kits (Linco Research, Millipore, Billerica, MA, USA).

Islet morphological analysis Isolated pancreases were prepared and labelled for insulin and glucagon as described [28]. Slides were digitised on a bright-field scanner at magnification of $\times 20$ and analysed with a software package (ImageScope; Aperio Technologies, Vista, CA, USA) using the positive-pixel count algorithm. Results were normalised to whole-slice area (total pixel count). Beta and alpha cell mass was determined using the total pancreatic weight. Islet number per slice was manually counted and normalised to whole-slice area. For islet size measurements, images were acquired on a confocal microscope using a software package (LSM510; Zeiss) at magnification of $\times 20$, after which the area of each islet was calculated using ImageScope (Aperio).

Zinc content measurement Cell zinc content was measured using Zinquin (Mellitech, Grenoble, France) as described $[13,33]$.

Insulin secretion Insulin secretion was assessed by islet perifusion as described [30]. Area under the curve was calculated using Graph Pad Prism.

Statistical analysis One-way repeated measures ANOVA with Tukey-Kramer or Bonnferroni's post hoc test was used for the oral glucose tolerance test (OGTT) and islet perifusion experiments, to determine significant variation in blood glucose levels and insulin secretion. In all other experiments, Student's $t$ test was used. A value of $p<0.05$ was considered statistically significant. Data are expressed 
as mean \pm SEM. The $n$ values represent the number(s) of animals used.

\section{Results}

ZnT8 localized to granules in beta and alpha cells Co-staining for ZnT8 and insulin/glucagon in mouse islets confirmed our previous findings $[12-14,19]$ that ZnT8 is present in beta and alpha cells (Fig. 1a). Not all dispersed cells were stained for ZnT8 (ESM Fig. 1) and based on previous studies, these cells may be delta cells $[19,34]$. In Nicolson et al, we have also shown that ZnT8 immunoreactivity is also absent in acinar cells [13]. To date such immunostaining studies have been the only means to suggest localisation of ZnT8 to insulin granules $[10,13]$, while ultrastructural localisation of ZnT8 in alpha cells is currently unknown. Here, however, we confirm, using transmission electron microscopy, that ZnT8 is indeed localised within the granules of mouse and human beta cells (Fig. 1b, ESM Fig. 2), as well as in non-beta cells (ESM Fig. 2), which we suggest to be alpha cells.

ZnT8 eliminated in Znt8BKO mouse islets Znt8BKO mice were generated as described in the Methods (Fig. 2a, b). The production of ZnT8 in islets was significantly reduced in Znt8BKO mice as determined by western immuno-blot
Fig. 1 ZnT8 levels in beta and alpha cells of mouse islets. a Dispersed islet cells were immunostained for ZnT8 (red) and insulin (Ins, green) or glucagon ( $\mathrm{Gcg}$, green). Yellow (merged images) indicates colocalisation of ZnT8 and insulin or glucagon. Scale bar $20 \mu \mathrm{m}$. b Electron micrographs of immuno-gold-labelled insulin and $\mathrm{ZnT} 8$ (arrows) in mouse islet cells at lower and higher magnification in small (scale bar $400 \mathrm{~nm}$ ) and large (scale bar $200 \mathrm{~nm}$ ) images respectively

\section{a}
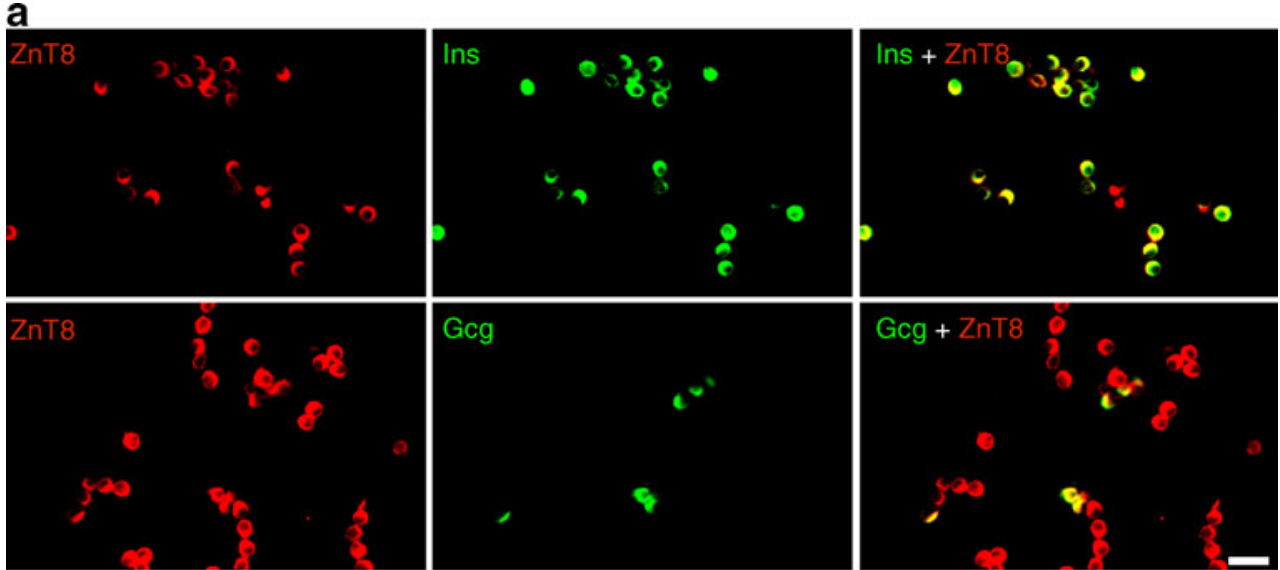

b
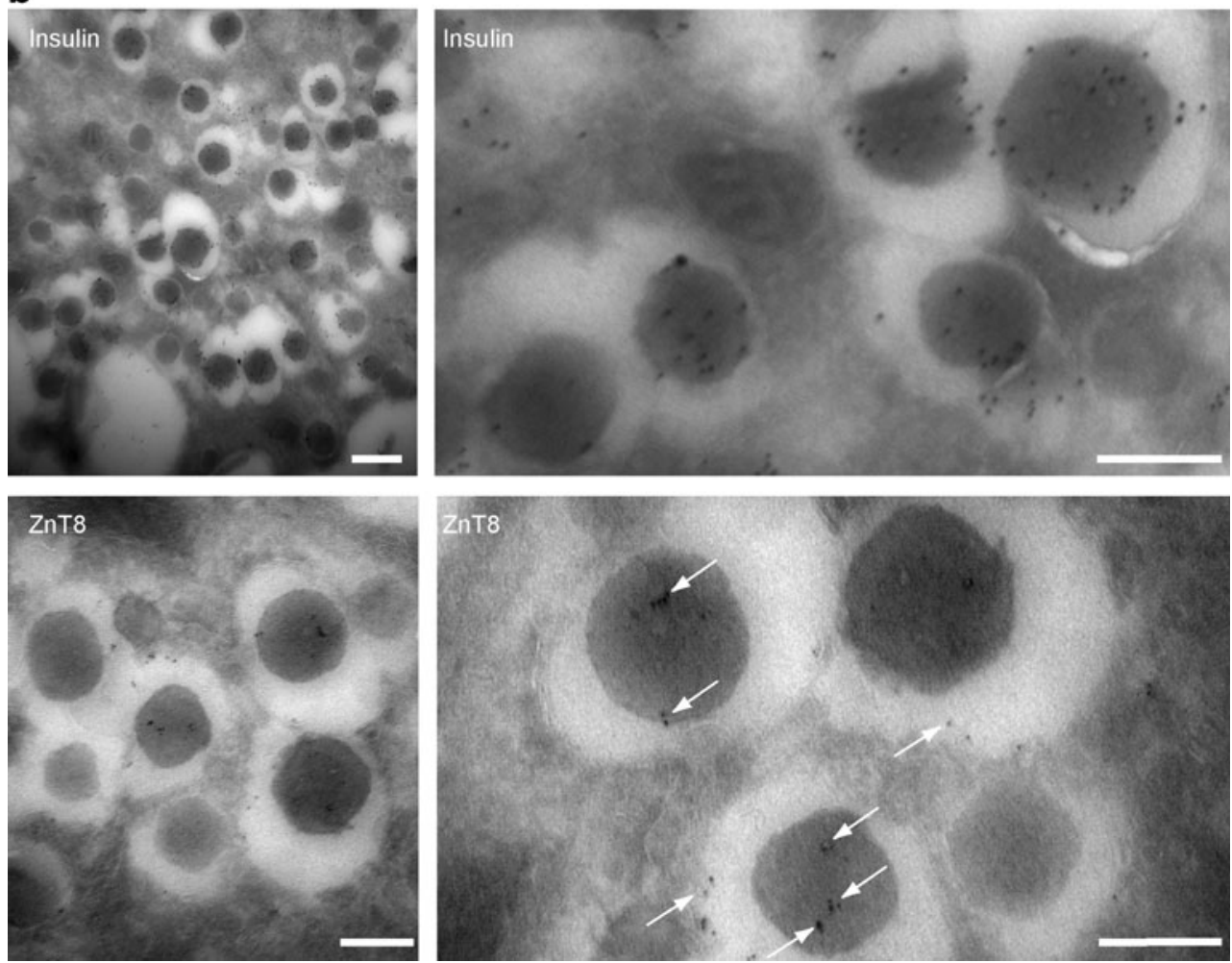
(Fig. 2d) and qPCR (Fig. 2e) analysis. The latter revealed approximately $90 \%$ reduction in Znt 8 mRNA in Znt8BKO islets compared with controls. Immunostaining experiments showed that dispersed islet cells positive for insulin in Znt8BKO mice were negative for ZnT8 (Fig. 2f). Those negative for insulin were positive for ZnT8. Conversely, in control islets, all insulin-positive cells were positive for ZnT8. This shows selective Znt8 deletion in beta cells of Znt8BKO islets. qPCR analysis indicated no compensatory changes in the expression of genes encoding other $\mathrm{ZnT}$ isoforms (Fig. $2 \mathrm{~g}$ ) or of the $\mathrm{Ca}_{\mathrm{v}} 1.1,1.2$ and 1.3 subunits that form L-type calcium channels (ESM Fig. 3), which also contribute to zinc transport in beta cells [33].

Znt8BKO mice are glucose-intolerant We have previously shown that male Znt8KO mice are mildly hyperglycaemic and glucose-intolerant as early as 6 weeks of age [13], while others have shown normal glucose homeostasis up to 1 year of age $[12,14]$. The current study shows that Znt8BKO mice have similar body weights (Fig. 3a) and fasting blood glucose (Fig. 3b) to control mice, but are glucose-intolerant (Fig. 3c; as measured by the area under the OGTT curve; Fig. 3d), also as early as 6 weeks of age. Interestingly, plasma insulin measurements during the OGTT showed no difference between groups (Fig. 3e, f). HOMA-IR indices (measurement of insulin resistance) were therefore also similar in control and Znt8BKO mice (3.32 \pm 0.55 and $3.71 \pm 0.54$ respectively).

Znt8BKO mice show abnormal beta cell morphology, reduced islet insulin processing and beta cell zinc accumulation Islet morphological analysis revealed that restricting Znt8 knockdown to beta cells had no effect on islet architecture, with no clear differences in islet size (Fig. 4a, b), islet number (Fig. 4c), beta cell mass (Fig. 4d, e) or alpha cell mass (Fig. 4f, g) observed between Znt8BKO mice and controls. In contrast, beta cell granule morphology was significantly altered in these mice compared with controls. We observed a reduction in the total number of granules and dense-core granules per given area, and an increase in the number of empty, light-core (grey) and atypical (rod-shaped) granules in beta cells from Znt8BKO mice (Fig. 4h-j), suggesting defective insulin crystallisation and packaging.
Fig. 2 Generation of Znt8BKO and Znt8AKO mice.

a Schematic diagram of the targeting construct for Znt8 showing (from top to bottom) the floxed region, RIP-Cre and Gcg-Cre-YFP transgene constructs. ATG, start codon; FRT, flippase recognition target; Flp, flippase recombination enzyme; Ex, exon; EYFP, enhanced yellow fluorescent protein. b PCR results of genotyping from tail biopsies of Znt8loxP and RIP-Cre mice. $\mathbf{c}$ qPCR analysis of $Z n t 8$ in wild-type mouse islets (grey bar) and hypothalamus (Hyp, black bar), $n=3-9, * * * p<0.001$. d Western blot and (e) qPCR analysis of $\mathrm{ZnT} 8$ in isolated islets from control (white bar) and Znt8BKO (black bar) mice, $n=5, * * p<0.01$. f Dispersed islet cells from control and Znt8BKO mice were immunostained for ZnT8 (red) and insulin (Ins, green). Yellow (merged images) indicates colocalisation of ZnT8 and insulin. Scale bar, $20 \mu \mathrm{m}$. g qPCR analysis of other $\mathrm{ZnT}$ transporters in isolated islets from control (white bar) and Znt8BKO (black bar) mice; $n=4$ a

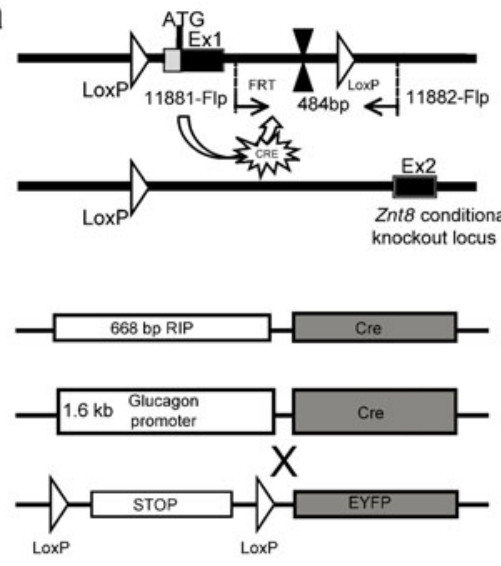

b

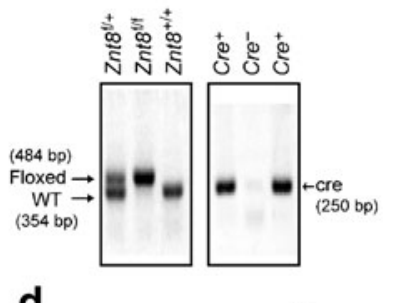

d

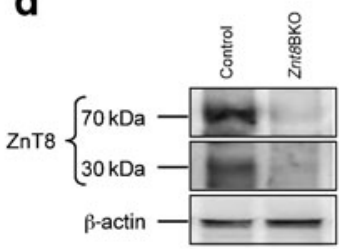

C

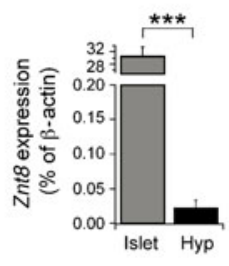

e

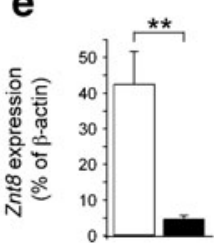

f

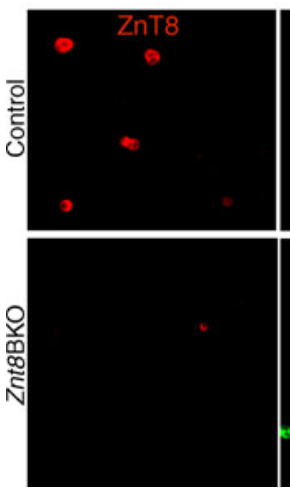

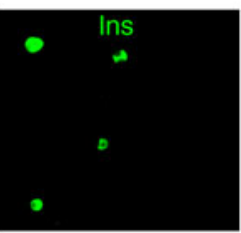
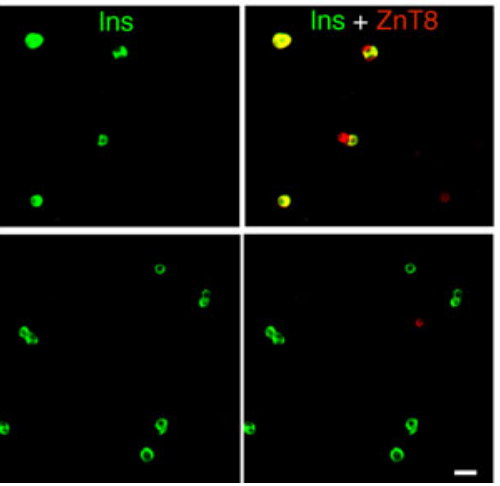

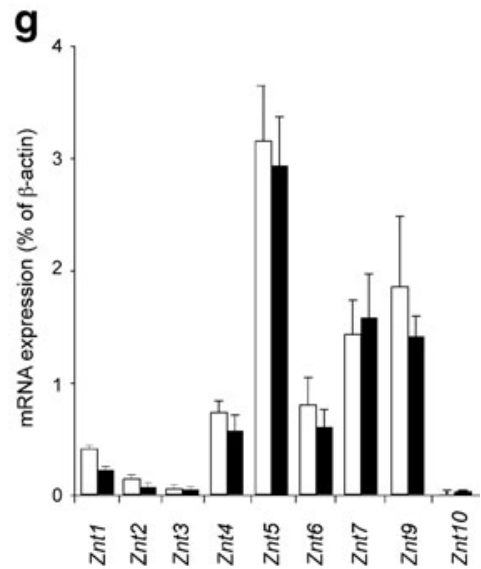




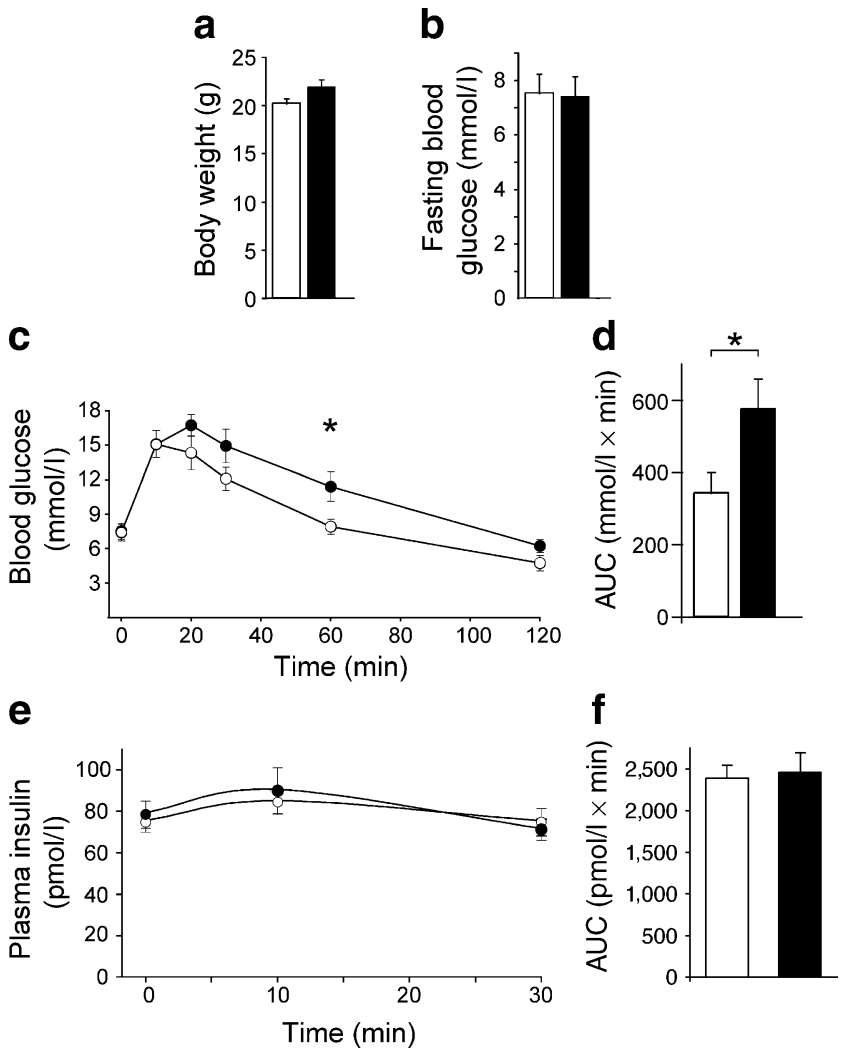

b

Fig. 3 In vivo characterisation of ZnT8BKO mice. a Body weight, (b) $6 \mathrm{~h}$ fasting blood glucose and (c) blood glucose during OGTT, with (d) area under glucose curve; ${ }^{*} p<0.05$. e Plasma insulin during OGTT with (f) area under insulin curve. Glucose dose $1.5 \mathrm{~g} / \mathrm{kg}$ body weight, in 6-week-old control (white bars/symbols) and ZnT8BKO (black bars/symbols) mice; $n=11$

Interestingly, Znt8BKO mice had significantly more plasma proinsulin in fed and fasting conditions, while plasma insulin levels were unaltered (Fig. 5a-d). Similarly, proinsulin content in Znt8BKO islets was also increased compared with controls (Fig. 5e), suggesting defective insulin processing in these mice. In addition, mRNA expression of the transcription factors $P d x 1$ and $M a f a$, and the processing enzymes prohormone convertase 1 and 2, and carboxypeptidase E, which are involved in insulin biosynthesis, were reduced in Znt8BKO islets compared with controls, although Insulin 1 and 2 mRNA was only slightly reduced (Fig. 5f-h). Interestingly, Kcnj11, which encodes the potassium inwardly rectifying channel, subfamily J, member 11, was also reduced in Znt8BKO mice. Static zinc content measurements revealed a reduction in zinc accumulation in dispersed islet cells from Znt8BKO mice compared with controls (Fig. 6a, b).

Znt8BKO mice show a reduced first-phase insulin response When isolated islets were perifused with low $(2.8 \mathrm{mmol} / \mathrm{l})$ and high $(11 \mathrm{mmol} / \mathrm{l})$ glucose or $10 \mathrm{mmol} / \mathrm{l}$ arginine
(Fig. 6c), we observed reduced first-phase insulin secretion from Znt8BKO islets compared with controls (as measured by the area under the OGTT curve; Fig. 6d). Second-phase insulin secretion and the response to arginine were not significantly different between groups.

Znt8AKO mice maintain normal plasma glucagon and glucose homeostasis Immunostaining for ZnT8 and YFP showed that dispersed islet cells positive for YFP in Znt8AKO mice were negative for $\mathrm{ZnT}$, indicating that alpha cells expressing Cre recombinase lacked Znt8 expression (Fig. 7a). It was previously found that $76 \%$ of alpha cells produce YFP [27]. However, Znt8AKO mice showed no evidence of glucose homeostasis abnormalities. Body weight gain (Fig. 7b), fasting plasma glucagon levels (Fig. 7c), glucose tolerance (Fig. 7d, e) and plasma insulin levels (Fig. 7f, g) were similar in Znt8AKO and control mice.

\section{Discussion}

Zinc transport family member 8 has recently attracted much attention after the identification in genome-wide array studies of an association between a non-synonymous polymorphism in the Znt8 gene and increased risk of type 2 diabetes [1-5]. Although immunofluorescent co-staining has localised ZnT8 with insulin [10, 11], our study is the first to demonstrate this at the level of the granule, using transmission electron microscopy. Furthermore, although ZnT8 has been observed in alpha cells using immunostaining $[12-14,19]$ and qPCR analysis of highly purified primary mouse islet alpha cells [13], the subcellular localisation of the protein has remained uncertain. We provide evidence here that ZnT8 also resides within glucagon granules. In support of a role for zinc in glucagon processing or packaging, recent work by Egefjord and colleagues showed zinc concentrated in the alpha cell secretory granule periphery [20].

Until its link to diabetes was established, only a couple of studies had explored the role of ZnT8 in beta cells. These suggested that Znt8 overexpression increases, while knockdown decreases zinc accumulation and insulin secretion in cultured beta cells $[10,35]$. Since then, three independent groups have studied Znt8KO mice in order to understand the molecular link between ZnT8 and glucose homeostasis [12-14]. Although a significant loss of islet or beta cell zinc content was observed in all three studies, only Nicolson et al. reported significant glucose intolerance at most ages and in both sexes of Znt8KO mice, and decreased insulin secretion during intraperitoneal glucose challenge [13]. More importantly, the impact of Znt8 deletion on in vitro insulin secretion was variable [12-14], with Lemaire et al. 
a

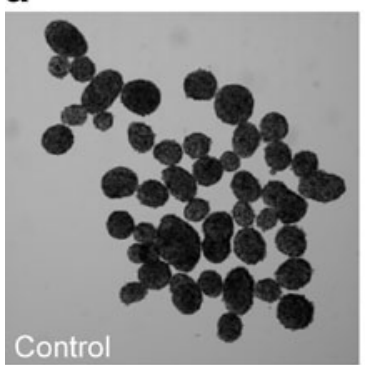

d

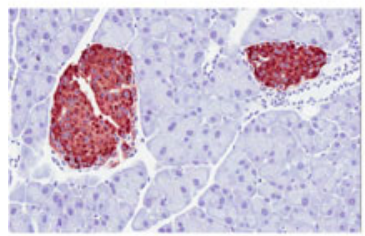

Control

h

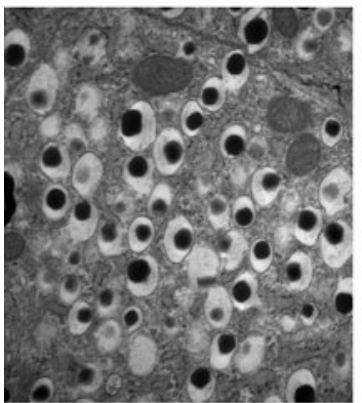

Control

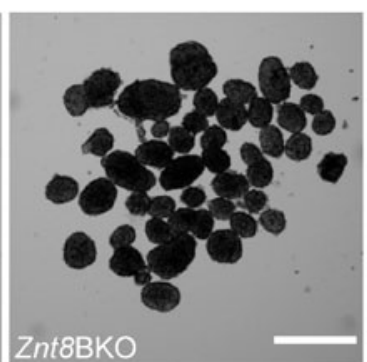

Znt8BKO

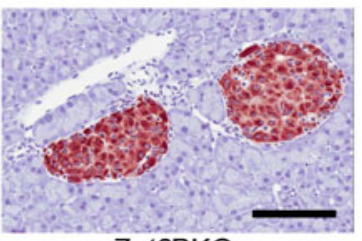

Znt8BKO b

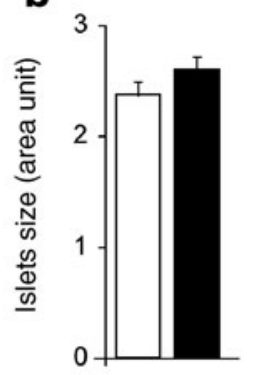

e

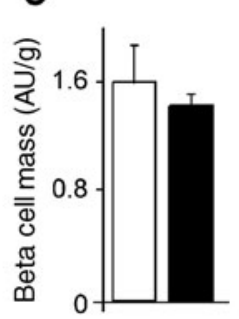

i

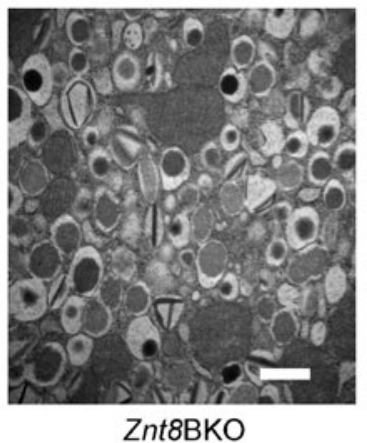

C

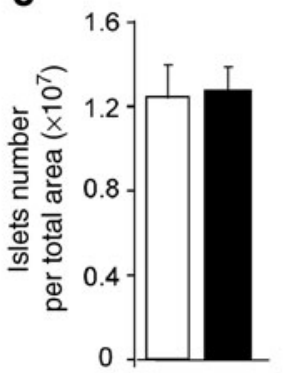

f
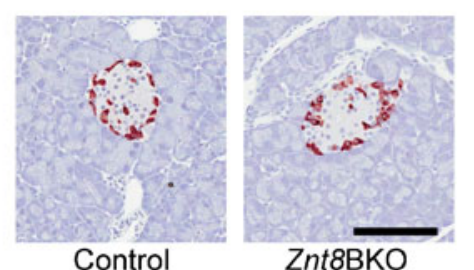

g

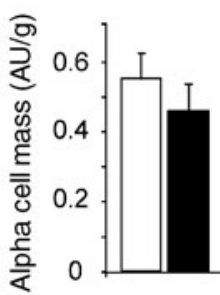

j

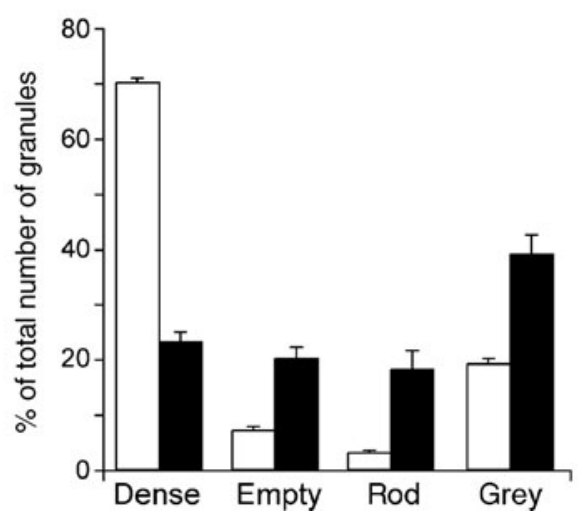

Fig. 4 Islet and beta cell morphological analysis in Znt8BKO (black bars) and control (white bars) mice. a Islet size as seen in representative images of isolated islets from control and Znt8BKO mice (scale bar $500 \mu \mathrm{m}$ ), with (b) bar graph showing quantification. c Islet number per pancreatic slice area (total pixel count); $n=2$. d Beta cell mass as shown in representative images of insulin staining (scale bar $200 \mu \mathrm{m}$ ), with (e) bar graph showing quantification and (f) alpha cell mass as shown in representative images of glucagon staining (scale bar, $200 \mu \mathrm{m}$ ) with (g) bar graph showing quantification; $n=2$; $\mathrm{AU}$, area unit. h Electron micrographs of isolated islets from control and Znt8BKO mice. Scale bar, $500 \mathrm{~nm}$. Manual quantifications, as shown in bar graphs $(\mathbf{i}, \mathbf{j})$, were performed on 20 sections from five islets per mouse; $n=2$
[12] showing no effect, Pound et al. [14] showing a decrease and Nicolson et al. [13] showing enhanced insulin secretion from Znt8KO mouse islets under the conditions studied. While pancreatic or islet insulin content was unchanged in all three studies, Pound et al. [14] showed reduced fasting plasma insulin in Znt8KO mice; this was in contrast to the other two studies, which showed no change $[12,13]$. These differences have been attributed to possible variations in genetic background, age and diet of the mice [36].

To provide a more appropriate model to understand ZnT8 specifically in the beta cell, we have now created
Znt $8 \mathrm{BKO}$ mice. The key findings in Znt $8 \mathrm{BKO}$ mice are glucose intolerance, reduced beta cell zinc accumulation and atypical insulin granules. In vitro, we demonstrated reduced first-phase glucose-stimulated insulin secretion in Znt8BKO mice, although plasma insulin was similar between groups during OGTT. Reasons for these differences remain unclear and require further investigation.

Our findings are in part consistent and partly inconsistent with the Znt8KO phenotype [12-14]. Since Znt8 expression is not restricted to the beta cell [16-18], differences in glucose homeostasis between Znt8KO and Znt8BKO mice could be due to Znt8 deletion in other cell 
a

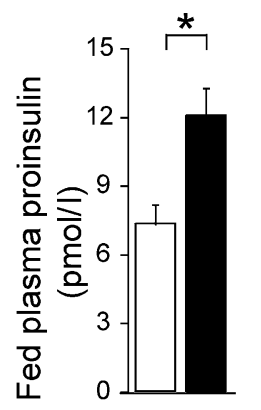

f

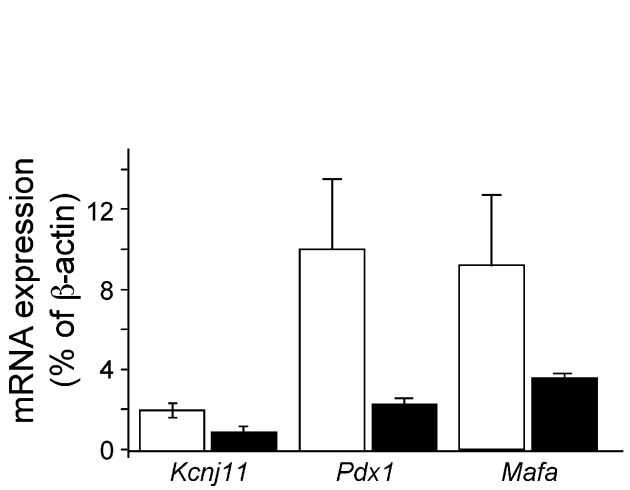

g

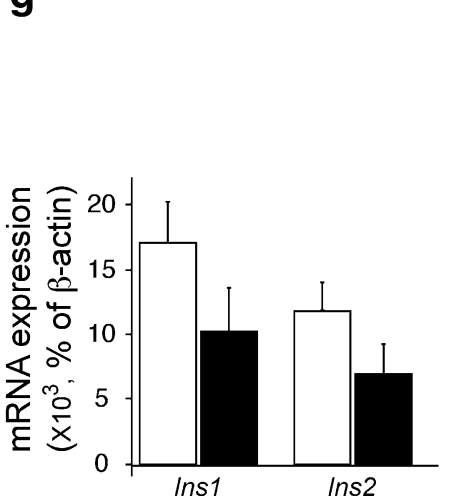

d

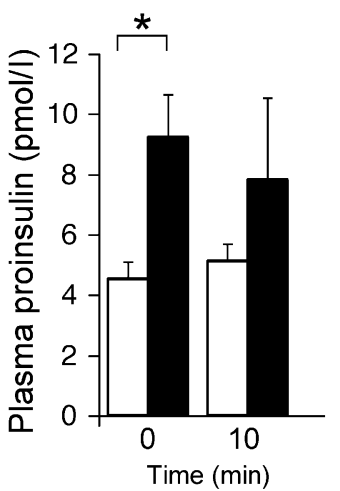

e

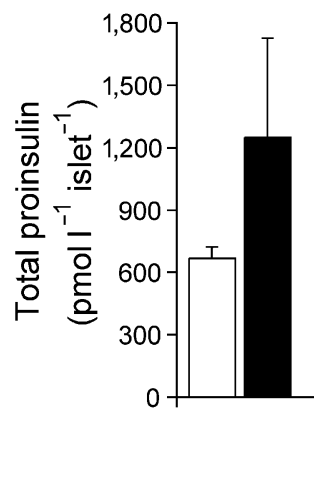

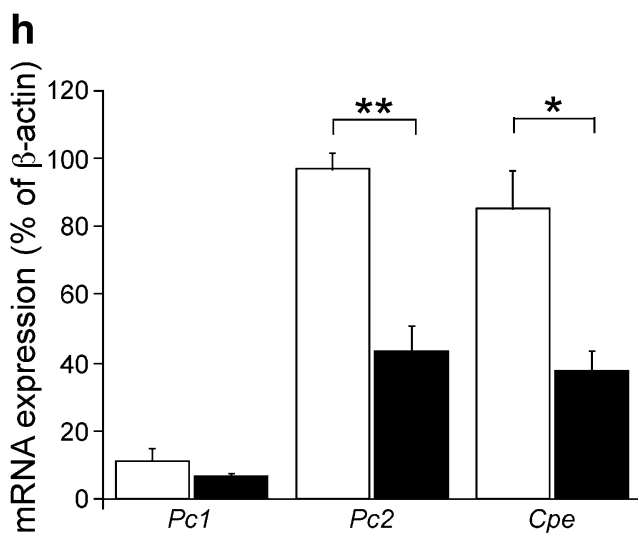

Fig. 5 Analysis of insulin processing in Znt8BKO (black bars) and control (white bars) mice. a Fed plasma proinsulin, (b) insulin and (c) proinsulin to insulin ratio; $n=4$. d Plasma proinsulin during OGTT

types and compensatory changes at these sites. ZnT8 is present in the alpha cell, adipose tissue and the adrenal cortex, which are well-known sites for regulation of glucose homeostasis [37-39]. It is also possible that low but significant expression of Znt8 centrally, including the hypothalamus, also influences the activity of neurons involved in control of feeding and satiety, or other aspects of energy homeostasis.

The mechanistic role of zinc in insulin biosynthesis has long been mapped out [40] (Fig. 8a, adapted from Dodson and Steiner [40]). Briefly, transcription of the insulin gene is mediated via the binding of transcription factors to conserved 5'-flanking region regulatory elements [41, 42]. Insulin, once translated, is directed into the endoplasmic reticulum as a single-chain molecule, from which a signal peptide is cleaved forming proinsulin [40]. Proinsulin is then transferred to the Golgi apparatus, an environment rich in zinc. Other studies show that ZnT5 is present in the Golgi and may be the primary transporter that moves zinc into this organelle [43]. Zinc-proinsulin hexamerisation, which introduces two zinc ions into each hexamer, followed by proinsulin to insulin conversion that is facilitated by prohormone convertases and carboxypeptidases occurs in (glucose dose $1.5 \mathrm{~g} / \mathrm{kg}$ body weight); $n=4$. e Total proinsulin content per islet; $n=4)$. $\mathbf{f}-\mathbf{h}$ mRNA expression of genes indicated in islets from control and Znt8BKO mice; $n=3$. * $p<0.05,{ }^{*} p<0.01$

early secretory vesicle [40, 44, 45]. Importantly, insulin crystallisation occurs within insulin granules, forming dense cores, in a process that requires up to 11 zinc ions per insulin hexamer [9]. Our data indicate that ZnT8 is localised to insulin granules (Fig. 1b) and represents the primary transporter that moves zinc into these organelles and is necessary for proper insulin crystallisation. Without $\mathrm{ZnT}$, zinc transport is reduced and dense-core granules rarely form (Figs 4e and 6a).

The significant reduction in insulin granule crystallisation leading to fewer dense-core granules is reminiscent of beta cells from animals with deficiencies in insulinprocessing enzymes [46, 47]. In addition to crystallisation, the increased presence of empty granules seen in Znt8BKO beta cells suggests a general defect in insulin packaging. Increased plasma and islet proinsulin, and reduced production of key transcription factors and insulin-processing enzyme genes in Znt8BKO mice suggest defects in both insulin transcription and processing (Fig. 8b). As zinc is an important co-factor for gene transcription, this reduction in expression of $P d x I$ and $M a f a$, as well as that of processing enzymes could be a general phenomenon of zinc deficiency in beta cells. In fact, several zinc-dependent transcription 
a

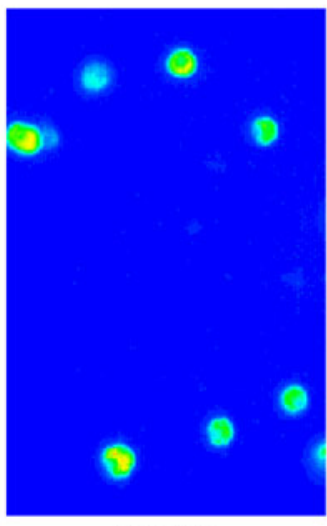

Control

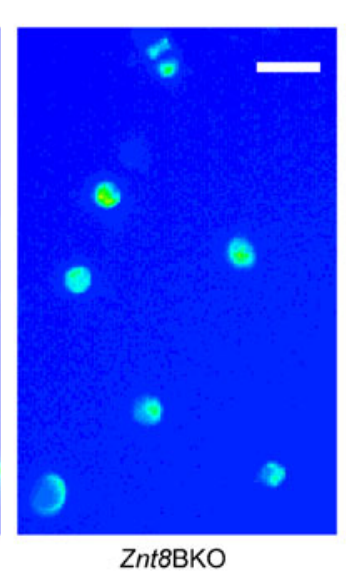

b

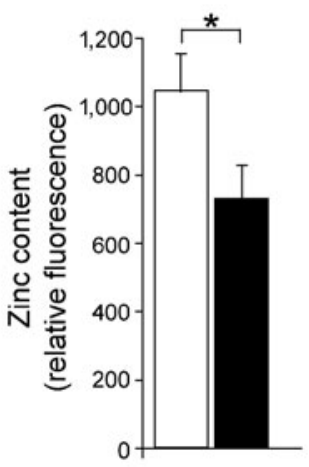

C

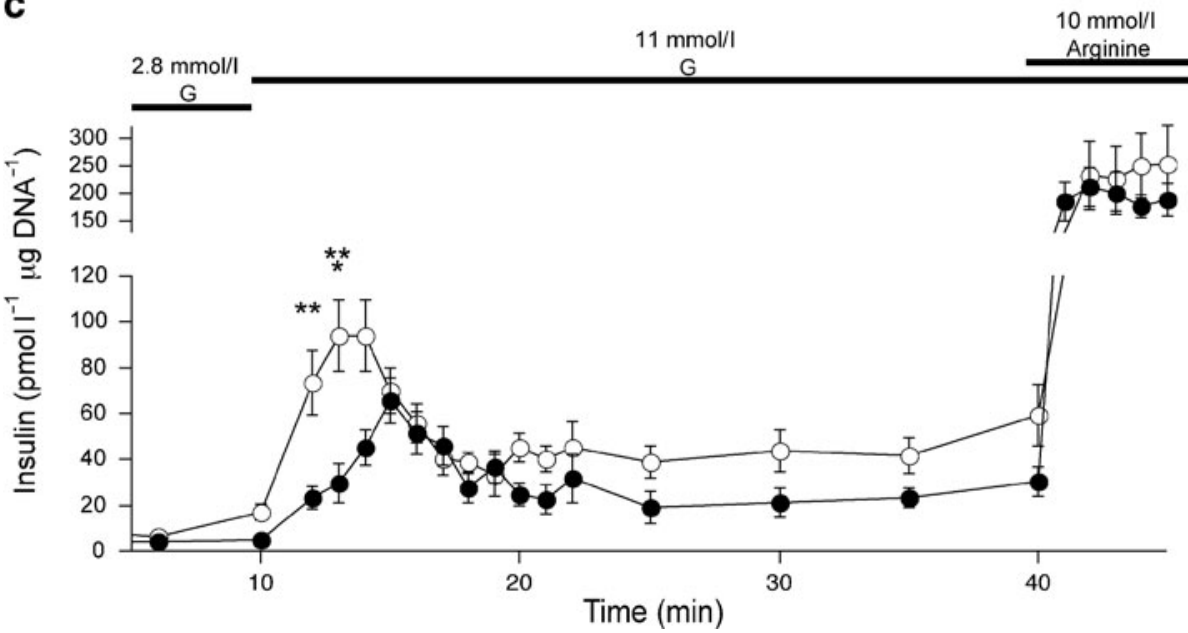

d

First phase

$(10-18 \mathrm{~min})$

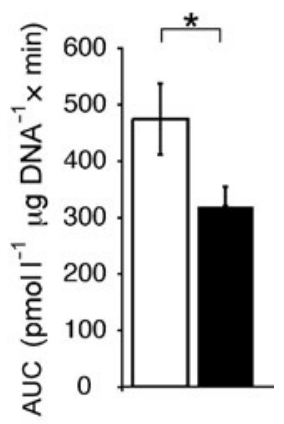

Fig. 6 Intracellular zinc content and in vitro insulin secretion from Znt8BKO (black bars/symbols) and control (white bars/symbols) islets. a Intracellular zinc content as estimated by zinquin and shown by representative images of dispersed islet cells loaded with zinquin; scale bar $10 \mu \mathrm{m}$; with (b) quantification by bar graph; $n=3$. c Insulin secretion from isolated islets during perifusion with 2.8 or $11 \mathrm{mmol} / 1$ glucose $(\mathrm{G})$ with or without $10 \mathrm{mmol} / \mathrm{l}$ arginine. d Area under the insulin curve from 10 to $18 \mathrm{~min} ; n=4 .{ }^{*} p<0.05,{ }^{*} p<0.01,{ }^{* * *} p<0.001$ factors are known to regulate $P d x 1$ and Mafa expression, possibly affecting insulin gene expression [48, 49]. As such, we observed a trend towards reduced insulin gene expression, but surprisingly failed to observe a corresponding decrease in plasma insulin. This may have been due to the inability of current methods to differentiate between proinsulin, insulin or other inactive forms. However, the more remarkable reduction in expression of genes encoding proinsulin-converting enzymes indicates that the principal impact is on post-translational modifications in the insulin biosynthetic pathway. The impaired conversion of proinsulin to insulin has also been observed in human carriers of the ZnT8 risk allele [50]. In vitro, Znt8BKO islets displayed reduced first-phase insulin secretion, which could have been due to reduced cargo or to the reduced or delayed exocytosis of insulin granules (Fig. 8b). Both scenarios are supported in the present study. First, indiscriminate exocytosis of granules regardless of maturity or crystallisation status including empty granules would lead to reduced secretion of biologically active insulin. In addition, Znt8BKO beta cells contain fewer granules per given area compared with control cells. Second, a zinc deficiency in Znt8BKO islets could affect the activity of zinc-dependent transcription factors and proteins associated with glucose sensing and the exocytotic machinery. For example, a decrease in expression of Kcnj11, as observed here, could affect glucose responsivity. Future studies will investigate these possibilities further.

Previously it has been shown that zinc regulates glucagon secretion from alpha cells [19, 22-24]; however, this is not a universal finding [13, 25, 39] and the mechanism of inhibition is still a matter of debate. Based on evidence that zinc inhibits glucagon secretion and that zinc and ZnT8 are localised to the alpha cell granule [20], 
Fig. 7 Characterisation of Znt8AKO mice. a Dispersed islets from control and Znt8AKO mice were immunostained for ZnT8 (red) and YFP (green). Yellow (merged images) indicates colocalisation of ZnT8 and YFP; scale bar $20 \mu \mathrm{m}$. b Body weight accumulation, (c) 16-h fasting plasma glucagon and (d, e) blood glucose during OGTT, with area under glucose curve; $n=10$. $\mathbf{f}$ Plasma insulin during OGTT, with $(\mathbf{g})$ area under the insulin curve; $n=5-8$. Glucose dose $2 \mathrm{~g}$ / $\mathrm{kg}$ body weight in 10 -week-old control (white bars/symbols) and Znt8AKO (black bars/symbols) mice
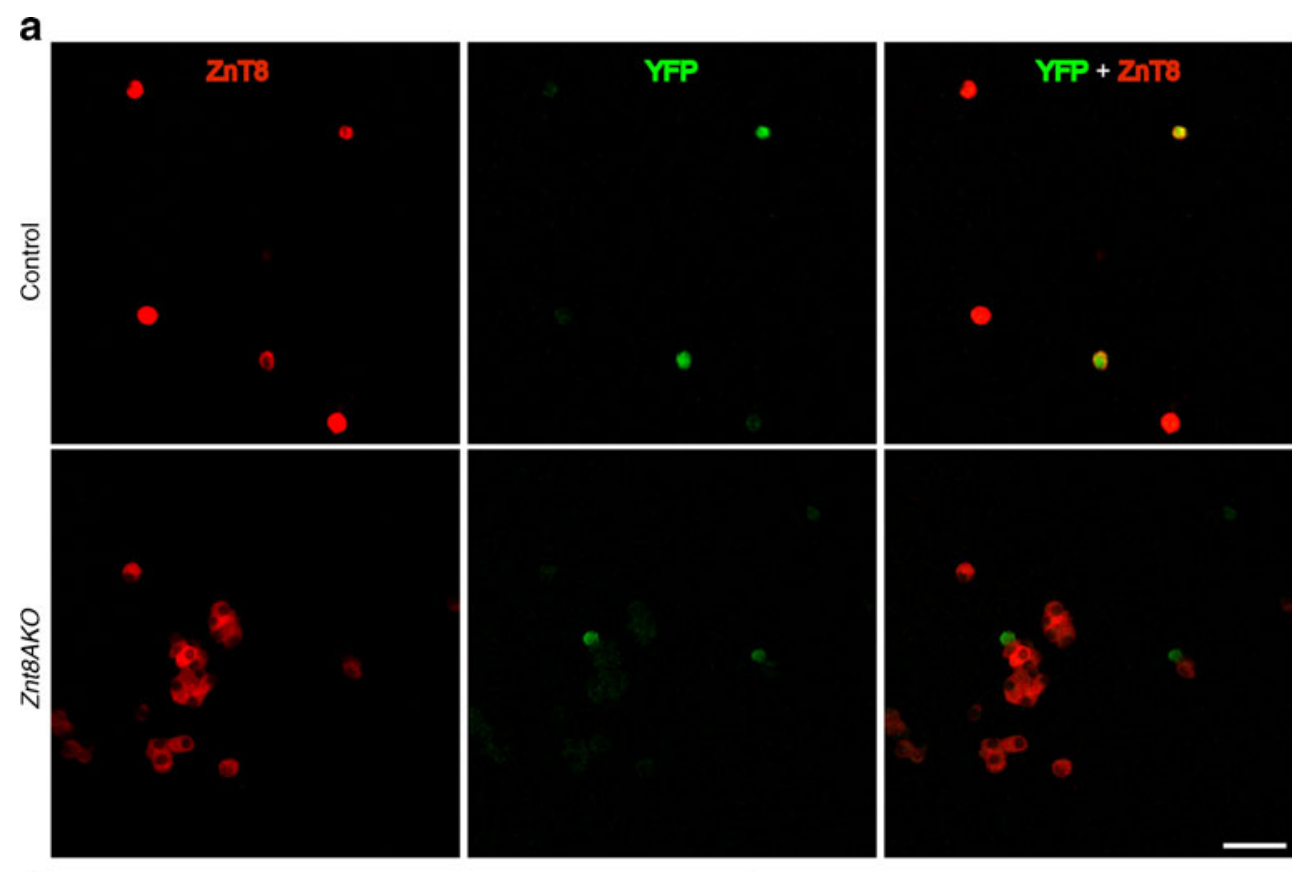

b
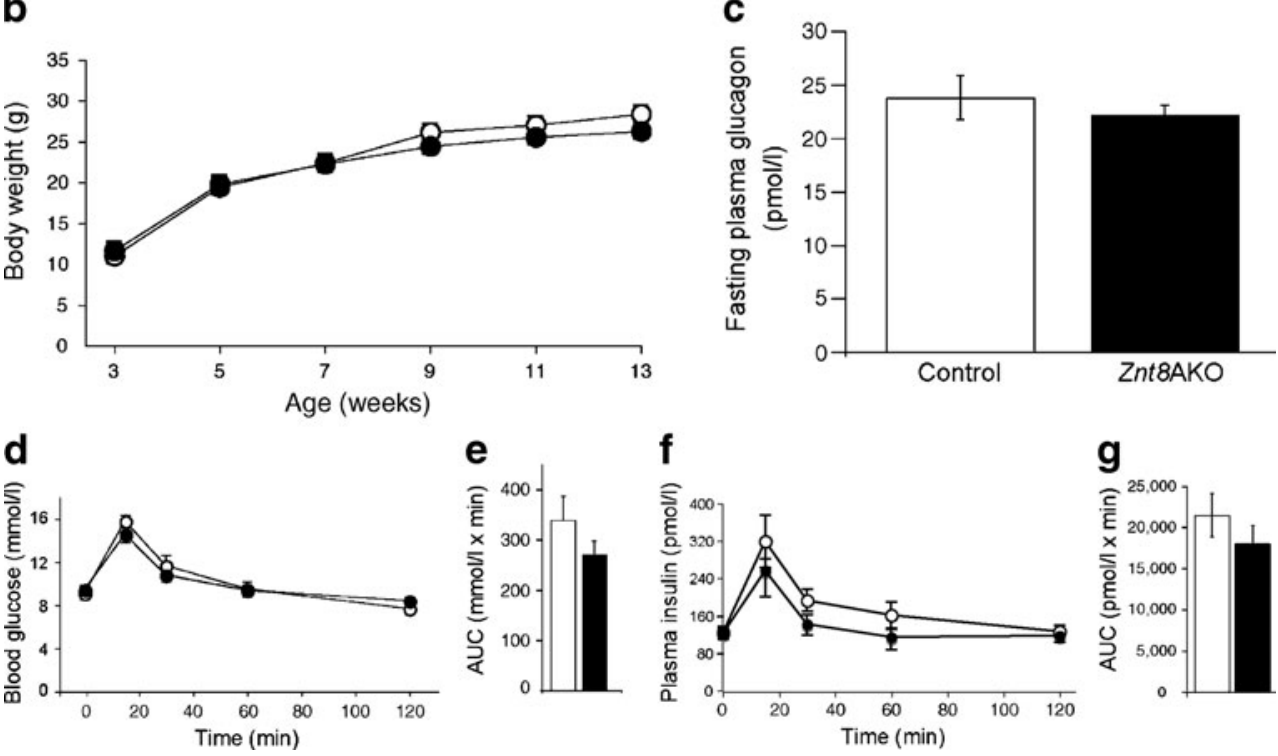

In conclusion, we provide the first report of specific beta and alpha cell deletion of Znt8. Our study suggests that ZnT8 does not have a major role in glucagon biosynthesis and secretion. In contrast, we demonstrate that $\mathrm{ZnT} 8$ is required for proper insulin processing, crystallisation and packaging, and that this in turn is required to maintain normal insulin secretion and glucose homeostasis (Fig. 8b). The similarities between Znt8KO and Znt8BKO mice make it apparent that the phenotype of the former is indeed primarily a consequence of Znt8 deletion in beta cells and not in alpha cells or at other sites of ZnT8 activity, where the differences may have arisen due to compensation at these other sites in Znt8KO mice. Interestingly, the and ZnT8 in this cell type. 
Fig. 8 Role of ZnT8 and zinc in insulin biosynthesis and secretion in (a) control and (b) Znt8BKO mouse beta cells, with stages numbered. Insulin transcription is mediated via transcription factors such as PDX1 and MAFA. Proinsulin synthesis occurs, followed by zinc-proinsulin hexamerisation. Loss of ZnT8, which is the primary zinc transporter on insulin granules, in Znt $8 \mathrm{BKO}$ beta cells reduces zinc content. Proinsulin to insulin conversion occurs, catalysed by prohormone convertase (PC)1, PC2 and carboxypeptidase $\mathrm{E}(\mathrm{CpE})$ enzymes. Enzyme levels are reduced in Znt8BKO beta cells, increasing proinsulin content. There is generation of densecore granules following insulin crystallisation. Reduced zincinsulin crystallisation, and increased levels of immature, abnormal and empty granules in Znt8BKO beta cells were observed. Insulin and zinc are released during granule exocytosis. Znt 8 BKO beta cells show reduced insulin and increased proinsulin secretion. Upward arrows, increase; downward arrows, decrease; inverted $\mathrm{T}$ symbol, inhibition. Adapted with permission from Dodson and Steiner [40] a

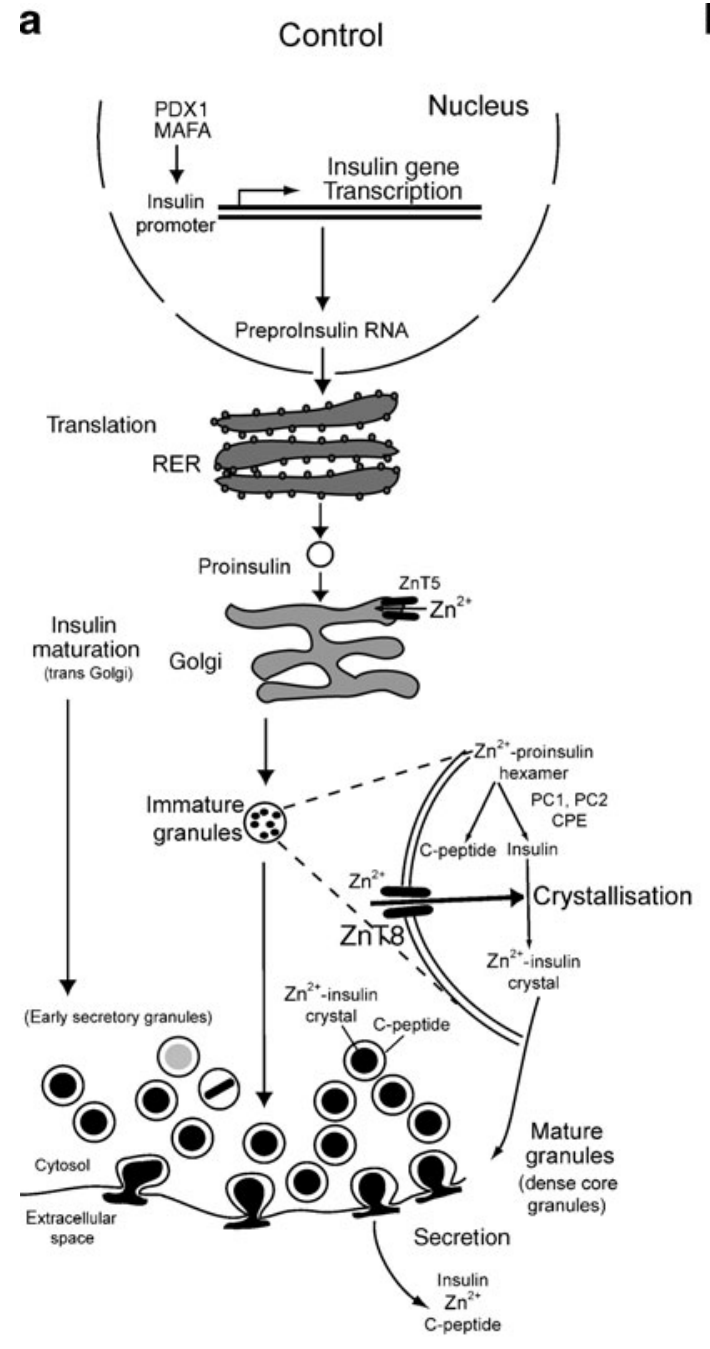

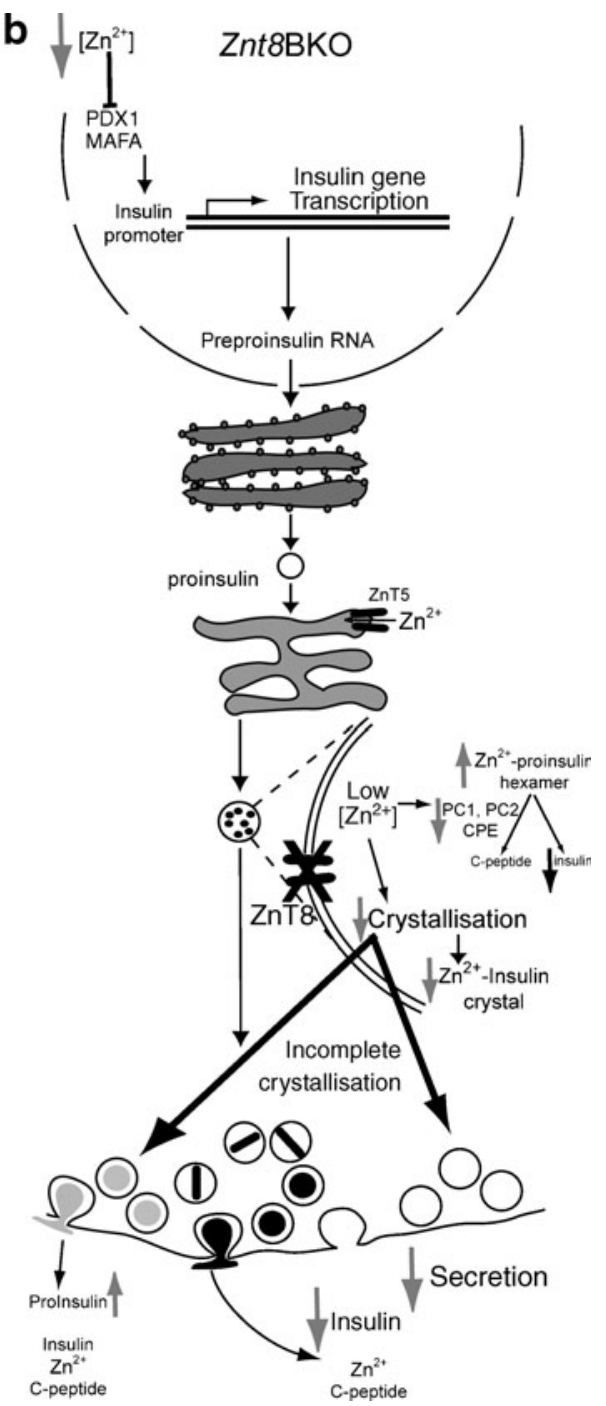

Znt8BKO phenotype has remarkably similar characteristics to human carriers of the risk allele of $\operatorname{ZnT8}[7,8,50]$, suggesting that it is a useful model to facilitate understanding of the molecular mechanisms linking Znt8 variants to the development of type 2 diabetes.

Acknowledgements This work was supported by a grant from the Canadian Institutes of Health Research (CIHR; MOP-102588) to M. B. Wheeler. A doctoral award from CIHR supported N. Wijesekara. G. A. Rutter was supported by Programme and Project grants from the Wellcome Trust, National Institutes of Health, Medical Research Council (UK), Juvenile Diabetes Research Foundation International, Diabetes UK and the European Union. We thank P. Herrera (University of Geneva Medical School, Department of Cell Physiology and Metabolism, Geneva, Switzerland) and P. Gilon (Unit of Endocrinology and Metabolism, University of Louvain Faculty of Medicine, Brussels, Belgium) for kindly providing Gcg-Cre-YFP mice. RIP-Cre mice were generously given by $\mathrm{M}$. Woo (Ontario Cancer Institute/Princess Margaret Hospital, Toronto, ON, Canada). We also thank R. Temkin (Advanced Bioimaging Centre, Mount Sinai Hospital, Pathology and
Laboratory Medicine, Toronto, ON, Canada), S. Doyle and B. Calvieri (Microscopy Imaging Lab, University of Toronto, Toronto, ON, Canada), Y. Liu, L. Li and S. Sultan (Department of Physiology, University of Toronto, Toronto, ON, Canada) for their technical support, and E. Allister (Department of Physiology, University of Toronto, Toronto, ON, Canada) for a critical review of the manuscript.

Duality of interest G. A. Rutter has received grant support from Servier IdS (Suresnes, France). F. Chimienti is employed by Mellitech (Grenoble, France). All other authors declare that there is no duality of interest associated with this manuscript.

\section{References}

1. Sladek R, Rocheleau G, Rung J et al (2007) A genome-wide association study identifies novel risk loci for type 2 diabetes. Nature 445:881-885

2. Saxena R, Voight BF, Lyssenko V et al (2007) Genome-wide association analysis identifies loci for type 2 diabetes and triglyceride levels. Science 316:1331-1336 
3. Scott LJ, Mohlke KL, Bonnycastle LL et al (2007) A genomewide association study of type 2 diabetes in Finns detects multiple susceptibility variants. Science 316:1341-1345

4. Zeggini E, Weedon MN, Lindgren CM et al (2007) Replication of genome-wide association signals in UK samples reveals risk loci for type 2 diabetes. Science 316:1336-1341

5. Steinthorsdottir V, Thorleifsson G, Reynisdottir I et al (2007) A variant in CDKAL1 influences insulin response and risk of type 2 diabetes. Nat Genet 39:770-775

6. Wenzlau JM, Juhl K, Yu L et al (2007) The cation efflux transporter ZnT8 (Slc30A8) is a major autoantigen in human type 1 diabetes. Proc Natl Acad Sci USA 104:17040-17045

7. Staiger H, Machicao F, Stefan N et al (2007) Polymorphisms within novel risk loci for type 2 diabetes determine beta-cell function. PLoS One 2:e832

8. Cauchi S, Proenca C, Choquet H et al (2008) Analysis of novel risk loci for type 2 diabetes in a general French population: the D. E.S.I.R. Study. J Mol Med 86:341-348

9. Emdin SO, Dodson GG, Cutfield JM, Cutfield SM (1980) Role of zinc in insulin biosynthesis. Some possible zinc-insulin interactions in the pancreatic B-cell. Diabetologia 19:174-182

10. Chimienti F, Devergnas S, Pattou F et al (2006) In vivo expression and functional characterization of the zinc transporter ZnT8 in glucose-induced insulin secretion. J Cell Sci 119:4199-4206

11. Chimienti F, Devergnas S, Favier A, Seve M (2004) Identification and cloning of a beta-cell-specific zinc transporter, ZnT-8, localized into insulin secretory granules. Diabetes 53:2330-2337

12. Lemaire K, Ravier MA, Schraenen A et al (2009) Insulin crystallization depends on zinc transporter ZnT8 expression, but is not required for normal glucose homeostasis in mice. Proc Natl Acad Sci USA 106:14872-14877

13. Nicolson TJ, Bellomo EA, Wijesekara N et al (2009) Insulin storage and glucose homeostasis in mice null for the granule zinc transporter ZnT8 and studies of the type 2 diabetes-associated variants. Diabetes 58:2070-2083

14. Pound LD, Sarkar SA, Benninger RK et al (2009) Deletion of the mouse Slc30a8 gene encoding zinc transporter-8 results in impaired insulin secretion. Biochem J 421:371-376

15. Seve M, Chimienti F, Devergnas S, Favier A (2004) In silico identification and expression of SLC30 family genes: an expressed sequence tag data mining strategy for the characterization of zinc transporters' tissue expression. BMC Genomics $5: 32$

16. Smidt K, Pedersen SB, Brock B et al (2007) Zinc-transporter genes in human visceral and subcutaneous adipocytes: lean versus obese. Mol Cell Endocrinol 264:68-73

17. Overbeck S, Uciechowski P, Ackland ML, Ford D, Rink L (2008) Intracellular zinc homeostasis in leukocyte subsets is regulated by different expression of zinc exporters ZnT-1 to ZnT-9. J Leukoc Biol 83:368-380

18. Murgia C, Devirgiliis C, Mancini E, Donadel G, Zalewski P, Perozzi G (2009) Diabetes-linked zinc transporter ZnT8 is a homodimeric protein expressed by distinct rodent endocrine cell types in the pancreas and other glands. Nutr Metab Cardiovasc Dis 19:431-439

19. Gyulkhandanyan AV, Lu H, Lee SC et al (2008) Investigation of transport mechanisms and regulation of intracellular $\mathrm{Zn}^{2+}$ in pancreatic alpha-cells. J Biol Chem 283:10184-10197

20. Egefjord L, Petersen AB, Rungby J (2010) Zinc, alpha cells and glucagon secretion. Current Diabetes Reviews 6:52-57

21. Souza SC, Qiu L, Inouye KE, Roix JJ, Chen H (2009) Zinc transporter ZnT-8 regulates insulin and glucagon seretion in Min6 and aTC1-9 pancreatic cell lines. Diabetologia 51(Suppl 1):501

22. Zhou H, Zhang T, Harmon JS, Bryan J, Robertson RP (2007) Zinc, not insulin, regulates the rat alpha-cell response to hypoglycemia in vivo. Diabetes 56:1107-1112
23. Franklin I, Gromada J, Gjinovci A, Theander S, Wollheim CB (2005) Beta-cell secretory products activate alpha-cell ATPdependent potassium channels to inhibit glucagon release. Diabetes 54:1808-1815

24. Ishihara H, Maechler P, Gjinovci A, Herrera PL, Wollheim CB (2003) Islet beta-cell secretion determines glucagon release from neighbouring alpha-cells. Nat Cell Biol 5:330-335

25. Ravier MA, Rutter GA (2005) Glucose or insulin, but not zinc ions, inhibit glucagon secretion from mouse pancreatic alphacells. Diabetes 54:1789-1797

26. Nguyen KT, Tajmir P, Lin CH et al (2006) Essential role of Pten in body size determination and pancreatic beta-cell homeostasis in vivo. Mol Cell Biol 26:4511-4518

27. Quoix N, Cheng-Xue R, Guiot Y, Herrera PL, Henquin JC, Gilon P (2007) The GluCre-ROSA26EYFP mouse: a new model for easy identification of living pancreatic alpha-cells. FEBS Lett 581:4235-4240

28. Lee SC, Robson-Doucette CA, Wheeler MB (2009) Uncoupling protein 2 regulates reactive oxygen species formation in islets and influences susceptibility to diabetogenic action of streptozotocin. J Endocrinol 203:33-43

29. O'Gorman D, Kin T, Murdoch T et al (2005) The standardization of pancreatic donors for islet isolations. Transplantation 80:801-806

30. Hardy AB, Fox JE, Giglou PR et al (2009) Characterization of Erg $\mathrm{K}^{+}$channels in alpha- and beta-cells of mouse and human islets. $\mathrm{J}$ Biol Chem 284:30441-30452

31. Tam P, Mahfoud R, Nutikka A et al (2008) Differential intracellular transport and binding of verotoxin 1 and verotoxin 2 to globotriaosylceramide-containing lipid assemblies. J Cell Physiol 216:750-763

32. Michael J, Carroll R, Swift HH, Steiner DF (1987) Studies on the molecular organization of rat insulin secretory granules. J Biol Chem 262:16531-16535

33. Gyulkhandanyan AV, Lee SC, Bikopoulos G, Dai F, Wheeler MB (2006) The $\mathrm{Zn}^{2+}$-transporting pathways in pancreatic beta-cells: a role for the L-type voltage-gated $\mathrm{Ca}^{2+}$ channel. J Biol Chem 281:9361-9372

34. Tamaki M, Fujitani Y, Uchida T, Hirose T, Kawamori R, Watada $\mathrm{H}$ (2009) Downregulation of ZnT8 expression in pancreatic bcells of diabetic mice. Islets 1:124-128

35. Fu Y, Tian W, Pratt EB et al (2009) Down-regulation of ZnT8 expression in INS-1 rat pancreatic beta cells reduces insulin content and glucose-inducible insulin secretion. PLoS One 4:e5679

36. Rutter GA (2010) Think zinc: new roles for zinc in the control of insulin secretion. Islets $2: 1-2$

37. Kahn BB, Flier JS (2000) Obesity and insulin resistance. J Clin Invest 106:473-481

38. Leung K, Munck A (1975) Peripheral actions of glucocorticoids. Annu Rev Physiol 37:245-272

39. Gromada J, Franklin I, Wollheim CB (2007) Alpha-cells of the endocrine pancreas: 35 years of research but the enigma remains. Endocr Rev 28:84-116

40. Dodson G, Steiner D (1998) The role of assembly in insulin's biosynthesis. Curr Opin Struct Biol 8:189-194

41. Kataoka K, Han SI, Shioda S, Hirai M, Nishizawa M, Handa H (2002) MafA is a glucose-regulated and pancreatic beta-cellspecific transcriptional activator for the insulin gene. J Biol Chem 277:49903-49910

42. Ohlsson H, Karlsson K, Edlund T (1993) IPF1, a homeodomaincontaining transactivator of the insulin gene. Embo J 12:4251-4259

43. Kambe T, Narita H, Yamaguchi-Iwai Y et al (2002) Cloning and characterization of a novel mammalian zinc transporter, zinc transporter 5, abundantly expressed in pancreatic beta cells. J Biol Chem 277:19049-19055

44. Steiner DF, Rouille Y, Gong Q, Martin S, Carroll R, Chan SJ (1996) The role of prohormone convertases in insulin biosynthesis: 
evidence for inherited defects in their action in man and experimental animals. Diabetes Metab 22:94-104

45. Goodge KA, Hutton JC (2000) Translational regulation of proinsulin biosynthesis and proinsulin conversion in the pancreatic beta-cell. Semin Cell Dev Biol 11:235-242

46. Furuta M, Carroll R, Martin S et al (1998) Incomplete processing of proinsulin to insulin accompanied by elevation of Des-31, 32 proinsulin intermediates in islets of mice lacking active PC2. J Biol Chem 273:3431-3437

47. Naggert JK, Fricker LD, Varlamov O et al (1995) Hyperproinsulinaemia in obese fat/fat mice associated with a carboxy- peptidase E mutation which reduces enzyme activity. Nat Genet 10:135-142

48. Yang Y, Chang BH, Samson SL, Li MV, Chan L (2009) The Kruppel-like zinc finger protein Glis3 directly and indirectly activates insulin gene transcription. Nucleic Acids Res 37:2529-2538

49. Eto K, Kaur V, Thomas MK (2006) Regulation of insulin gene transcription by the immediate-early growth response gene Egr-1. Endocrinology 147:2923-2935

50. Kirchhoff K, Machicao F, Haupt A et al (2008) Polymorphisms in the TCF7L2, CDKAL1 and SLC30A8 genes are associated with impaired proinsulin conversion. Diabetologia 51:597-601 